\title{
Chemosensetizing and cardioprotective effects of resveratrol in doxorubicin- treated animals
}

\author{
Abdel-Moneim M Osman ${ }^{1,2^{*}}$, Sameer E Al-Harthi ${ }^{1,3}$, Ohoud M AlArabi ${ }^{1}$, Mohamed F Elshal ${ }^{3,4}$, Wafaa S Ramadan ${ }^{5,6}$, \\ Mohamed N Alaama ${ }^{7}$, Huda M Al-Kreathy ${ }^{1}$, Zoheir A Damanhouri ${ }^{1}$ and Osman H Osman ${ }^{1}$
}

\begin{abstract}
Background: Doxorubicin (DOX), an anthracycline antibiotic is one of the most effective anticancer drug used in the treatment of variety of cancers. Its use is limited by its cardiotoxicity. The present study was designed to assess the role of a natural product resveratrol (RSVL) on sensitization of mammary carcinoma (Ehrlich ascites carcinoma) to the action of DOX and at the same time its protective effect against DOX-induced cardiotoxicity in rats.

Methods: Ehrlich ascites carcinoma bearing mice were used in this study. Percent survival of tumor bearing mice was used for determination of the Cytotoxic activity of DOX in presence and absence of RSVL. Uptake and cell cycle effect of DOX in tumor cells in the presence of RSVL was also determined. Histopatholgical examination of heart tissues after DOX and/or RSVL therapy was also investigated.

Results: DOX at a dose level of $15 \mathrm{mg} / \mathrm{kg}$ increased the mean survival time of tumor bearing mice to 21 days compared with 15 days for non tumor-bearing control mice. Administration of RSVL at a dose level of $10 \mathrm{mg} / \mathrm{kg}$ simultaneously with DOX increased the mean survival time to 30 days with $70 \%$ survival of the tumor-bearing animals. RSVL increased the intracellular level of DOX and there was a strong correlation between the high cellular level of DOX and its cytotoxic activity. Moreover, RSVL treatment showed 4.8 fold inhibition in proliferation index of cells treated with DOX. Histopathological analysis of rat heart tissue after a single dose of DOX $(20 \mathrm{mg} / \mathrm{kg})$ showed myocytolysis with congestion of blood vessels, cytoplasmic vacuolization and fragmentation. Concomitant treatment with RSVL, fragmentation of the muscle fiber revealed normal muscle fiber.
\end{abstract}

Conclusion: This study suggests that RSVL could increase the cytotoxic activity of DOX and at the same time protect against its cardiotoxicity.

Keywords: Doxorubicin, Resveratrol, Potentiation, Cardioprotection, Cell cycle disturbance

\section{Introduction}

Doxorubicin (DOX) was introduced in cancer therapy in the late 1960s. It has emerged as one of the most potent broad-spectrum antitumor anthracycline antibiotics. DOX can be administered as a single agent or in combination with other chemotherapeutic agents. It is widely used in the treatment of variety of cancers, including leukemias, lymphomas, soft-tissue sarcomas, and solid tumors. Its cytotoxic effects on malignant cells, however, are complicated by an increase in the risk of cardiotoxicity $[1,2]$.

\footnotetext{
* Correspondence: moneimosman@hotmail.com

'Pharmacology Department, Faculty of Medicine, King Abdulaziz University, Jeddah, Saudi Arabia

${ }^{2}$ National Cancer Institute, Cairo University, Cairo, Egypt

Full list of author information is available at the end of the article
}

Due to the increasing worldwide prevalence and health burden of doxorubicin induced cardiotoxicity, it has become increasingly important to find pharmacological remedies to protect against this serious side effect, in an attempt to minimize DOX effective chemotherapeutic dose and thereby its side effects, a variety of approaches have been investigated [3-5]. One of them is the search for natural compounds with chemopreventive or anticancer properties that can be used in combination with doxorubicin. Resveratrol (RSVL) (trans - 3, 5, 4- trihydroxystilbene) is a naturaly occurring poly-phenolic compound found primarily in root extracts of the oriental plant Polygonum cuspidatum and many other plant species [6]. It is highly abundant in skins of red grapes and moderately abundant in peanuts and blueberries [6]. It has recently been

\section{Biomed Central}

(c) 2013 Osman et al.; licensee BioMed Central Ltd. This is an Open Access article distributed under the terms of the Creative Commons Attribution License (http://creativecommons.org/licenses/by/2.0), which permits unrestricted use, distribution, and reproduction in any medium, provided the original work is properly cited. 
Table 1 Effects of RSVL treatment (10 $\mathrm{mg} / \mathrm{kg}$,i.p.) on the therapeutic action of DOX ( $15 \mathrm{mg} / \mathrm{kg}$,i.p.) in mice bearing Ehrlich ascites carcinoma cells

\begin{tabular}{lll}
\hline Treatment & $\begin{array}{l}\text { Mean } \\
\text { survival time }\end{array}$ & $\begin{array}{l}\text { 45-day } \\
\text { survivors }\end{array}$ \\
\hline Control & $15 \pm 4.06^{\mathbf{a}, \mathbf{b}}$ & $0 / 10$ \\
RSVL (10 $\mathbf{~ g g / k g})$ & $13 \pm 3.55^{\mathbf{b}}$ & $0 / 10$ \\
DOX (15 $\mathbf{~ m g / k g )}$ & $21 \pm 9.19^{\mathbf{a}, \mathbf{b}}$ & $1 / 10$ \\
DOX (15 $\mathbf{~ g / / g})+$ RSVL (10 $\mathbf{~ m g / k g )}$ & $30 \pm 5.29^{\mathbf{a}, \mathbf{b}}$ & $7 / 10$ \\
(supplied simultaneously) & & \\
\hline
\end{tabular}

Each data represents the mean \pm S.D. of ten mice. The mean Survival time is the time in days until animals die.

${ }^{\text {a }}$ Significantly different from control at P-value $\leq 0.05$. ${ }^{\text {b }}$ Significantly different from DOX at P-value $\leq 0.05$.

discovered that it has many beneficial effects in different biological systems, which include anti-inflammatory, antioxidant, anti-neoplastic, anti-carcinogenic, anti-tumorigenic, cardioprotective, neuroprotective, anti-aging and antiviral effects [6]. Its potential chemopreventive and chemotherapeutic activities have been demonstrated in all three stages of carcinogenesis (initiation, promotion, and progression) [7]. A study from our lab used a model of DOX-induced heart damage in rats, we found that pre-treatment with aged garlic extract, a strong antioxidant, offered protection against DOX-induced myocardial cell damage [8]. Recently, Osman et al. [9] reported sensitization of human breast cancer cells to the action of DOX in an attempt to minimize DOX effective dose and thereby its side effects. Therefore The present study was undertaken to test whether resveratrol in vivo could potentiate the antitumor properties of doxorubicin and the mechanisms by which this could happen. Also could resveratrol protect against DOX-induced cardiotoxicity.

\section{Materials and methods Reagents}

Doxorubicin hydrochloride and RSVL were purchased from Sigma-Aldrich Co. (St. Louis, MO, USA). The stock solution of both drugs were dissolved in normal saline and preserved at $-20^{\circ} \mathrm{C}$. The solutions were diluted in normal saline immediately before each experiment to the desired final concentration.

\section{Animals and tumor}

Female Swiss albino mice (8 weeks of age, 20-25 g body weight) were obtained from King Fahd Medical Research Center, King Abdulaziz University, Jeddah, Saudi Arabia. The animals were acclimatized for one week. A commercial balanced diet and water, ad libitum were provided throughout the experiment. A line of Ehrlich ascites carcinoma cells (EAC) cells was supplied by Prof. Abdel-Moneim and maintained in our laboratory by weekly I.P. transplantation of $2.5 \times 10^{6}$ cells/mouse. This study was approved by the ethical committee of King Abdulaziz Hospital.

\section{Evaluation of antitumor activity}

The effect of RSVL on the antitumor activity of DOX was evaluated using the modified regimen of Donenko et al. [10]. In brief, EAC cells were inoculated I.P. into forty female Swiss albino mice $\left(2.5 \times 10^{6}\right.$ cells/mouse) . Twenty four hours later, mice were equally divided into four groups. Group 1: mice were administered normal saline i.p. $(0.2 \mathrm{ml} / 20 \mathrm{gm})$ and served as control. Group II was administered DOX $15 \mathrm{mg} / \mathrm{kg}$ i.p. Group III received a single dose of RSVL (10 mg/kg,i.p.) and Group IV received RSVL simultaneously with DOX.

\section{Assessment of doxorubicin cellular accumulation}

DOX cellular accumulation assessment in Ehrlich ascites cells was performed using spectrofluorometer (F-2000 Fluorescence spectrophotometer Hitachi, Japan) according to the method of Kitagawa et al. [11]. Ehrich ascites cells were inoculated as described above at $10 \times 10^{6}$ cells/mouse. Twenty-four hours later RSVL (15 mg/ $\mathrm{kg}$ ) was injected i.p. simultaneously with DOX $(20 \mathrm{mg} / \mathrm{kg})$. Tumor samples were obtained at fixed times after DOX treatment, washed, counted, and DOX fluorescence intensity was

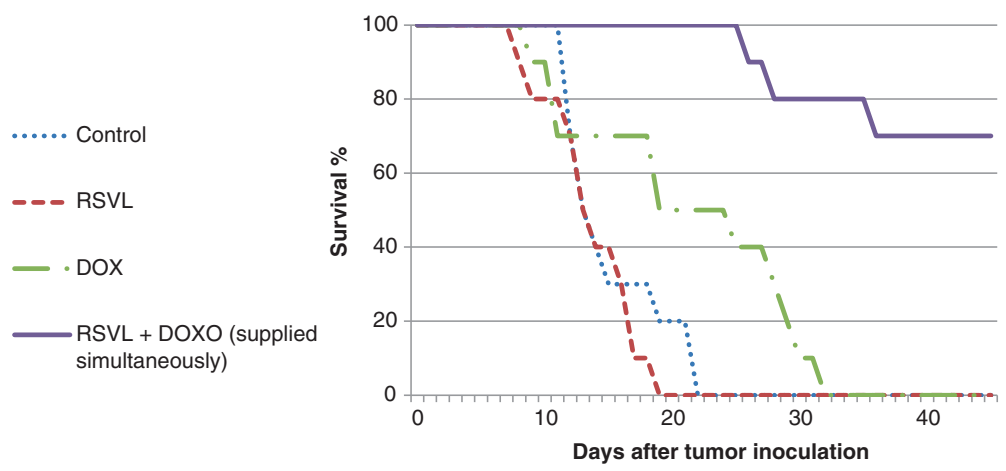

Figure 1 Effect of RSVL treatment (10 mg/kg,i.p.) on the cytotoxic activity of doxorubicin (10 mg/kg,i.p.) against the growth of Ehrlich ascites cells. 


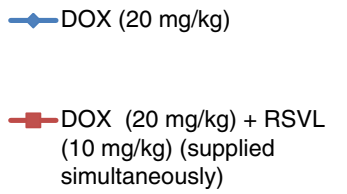

measured at excitation and emission wavelengths of $\lambda$ $\mathrm{ex}=496 \mathrm{~nm}$ and $\lambda \mathrm{em}=592 \mathrm{~nm}$, respectively to determine DOX concentration.

\section{DOX cellular accumulation ratio DOX concentration in RSVL treaated cells$$
=\overline{\text { DOX concentration in cells treated with DOX alone }}
$$

\section{Cell cycle analysis}

Ehrlich ascites cells were inoculated i.p. $\left(10 \times 10^{6}\right.$ cells/ mouse). Twenty-four hours later, DOX ( $20 \mathrm{mg} / \mathrm{kg}$,i.p.) was injected simultaneously with RSVL (10 mg/kg,i.p.). T umor cells were obtained at fixed times after DOX treatment. Cell cycle analysis was performed using flow cytometer (Becton Dicknson, BD, FACSCalbur, USA) according to the method of Smets et al. [12].

\section{Cardio toxic effect of DOX in presence of RSVL}

Twenty-five male Wistar rats were divied into five equal groups consisting of 5 animals each and housed in a room with regular $12 \mathrm{hr}$. light/dark cycle with free access to food and water. Two groups (I and II) were used as a control and received normal saline (i.p.) and RSVL (15 mg/kg,i.p.). Group III received a single dose of DOX at dose of $20 \mathrm{mg} / \mathrm{kg}$. Groups IV received DOX simultaneously with RSVL. Twenty four hours after DOX treatment, animals were anesthetized and heart specimens were fixed in $10 \%$ formalin for light microscopic study of the heart tissues.

\section{Statistical analysis}

Statistical analysis was performed using SPSS (statistical package of social sciences, version 16). One way analysis of variance (ANOVA) followed by least significant difference (LSD) for post hoc analysis, was used for multiple comparisons. Statistical significance was acceptable to a level of $\mathrm{p}<0.05$.

\section{Results}

\section{Survival of tumor bearing mice}

Table 1 and Figure 1 show the effect of treatment with DOX and/or RSVl on the survival of tumor bearing mice. Tumor-bearing control mice showed mean survival time of 15 days, whereas administration of a single dose of DOX (15 mg/kg,i.p.) increased the mean survival time to 21 days, with $10 \%$ long term survivors. Concomitant treatment with RSVL $(10 \mathrm{mg} / \mathrm{kg}$,i.p.) increased the mean survival time of tumor-bearing mice to 30 days with $70 \%$ long term survivors.

\section{DOX level in tumor cells}

Figure 2 shows the cellular level of DOX in Ehrlich ascites cells after a single dose of DOX $(20 \mathrm{mg} / \mathrm{kg}$,i.p. $)$ and/or RSVL (10 mg/kg,i.p.). RSVL significantly increased the cellular level of DOX at all the time points tested, the maximum level appeared 3 hours after treatment. Forty-eight hours after treatment the levels of DOX decreased but still higher after combination therapy (1.7 fold more). DOX cellular accumulation ration were 1.55, 1.85 and 1.67 after 3,24 and 48 hours after DOX treatment, respectively. 

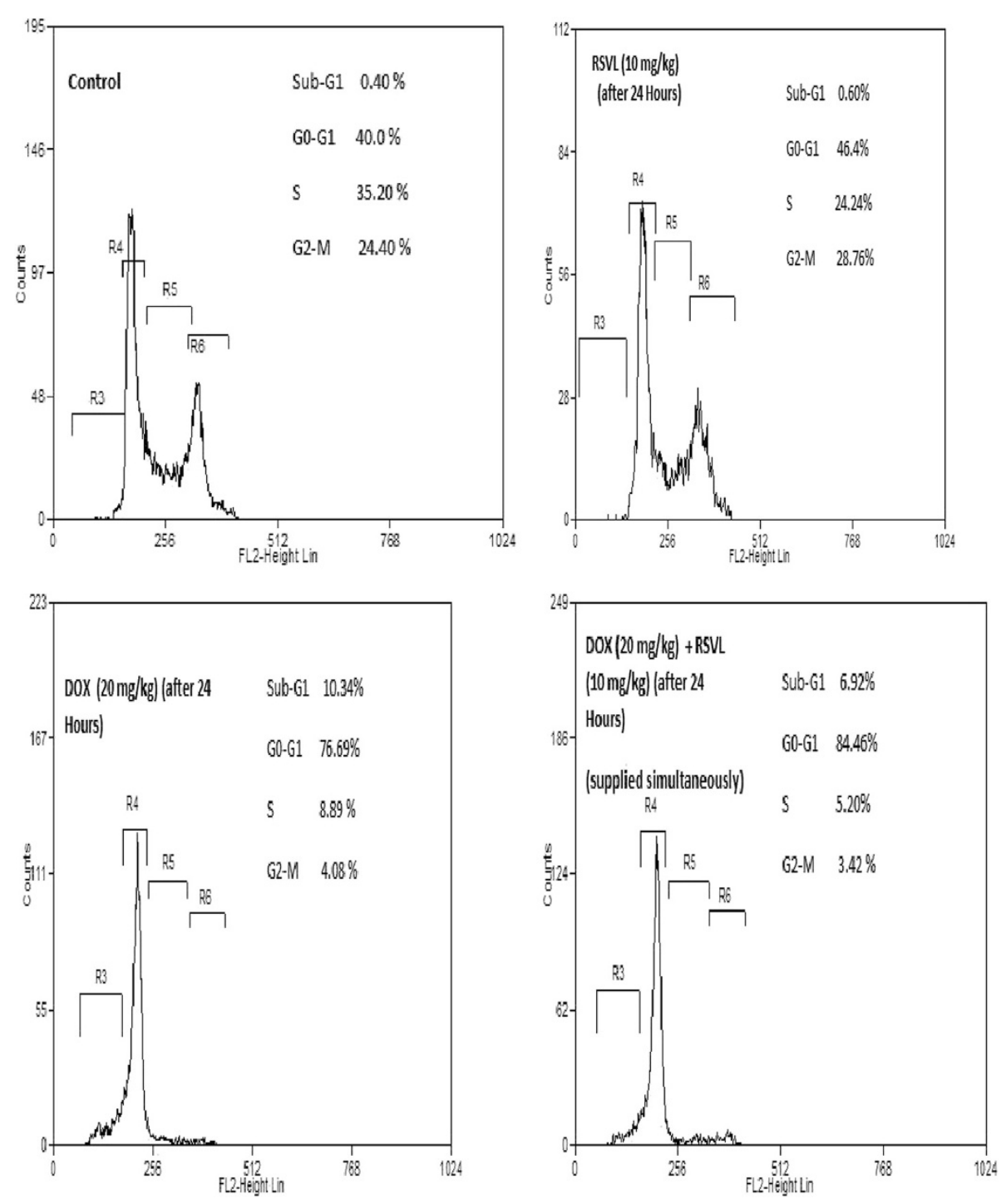

Figure 3 Effect of DOX (15 mg/kg) and/or RSVL (10 mg/kg) on cell cycle phase distribution of Ehrlich ascites cells.

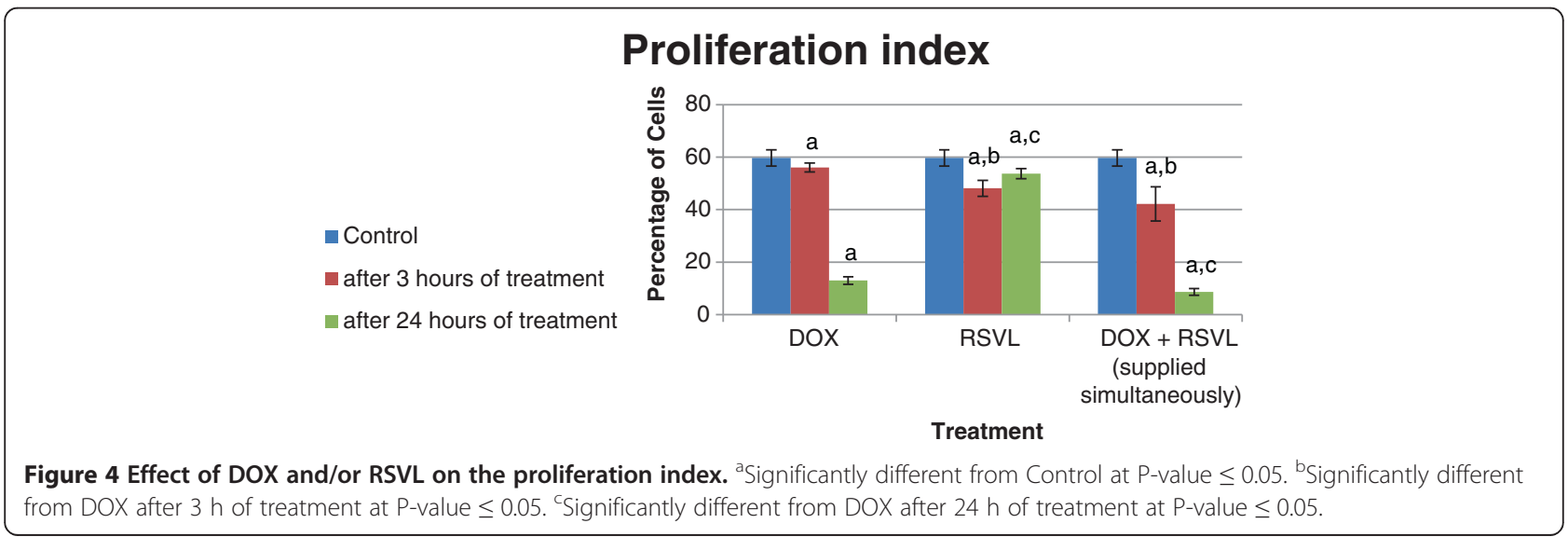




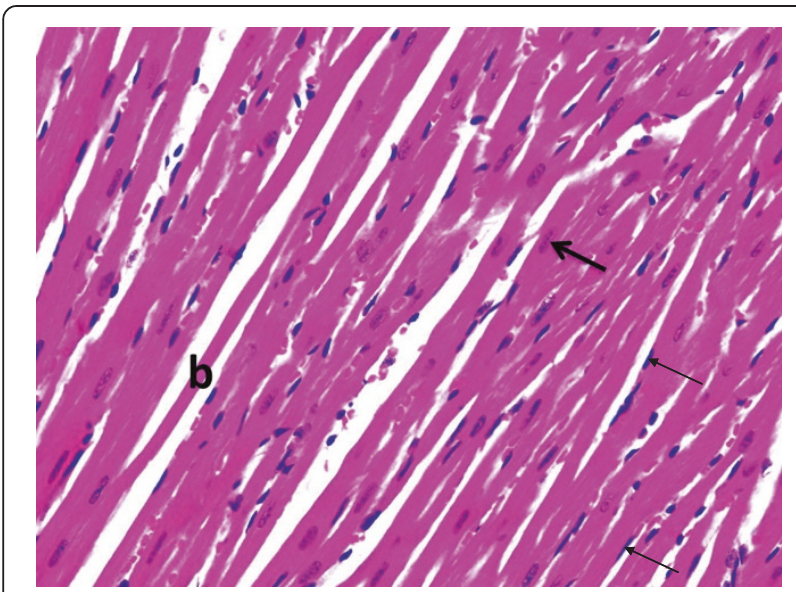

Figure $5 \mathrm{~A}$ photomicrograph of the myocardium of a normal rat showing branching cardiac muscle fibers (b) with central oval euchromatic nuclei (thick arrow). The fibroblast in the endomycium revealed deeply stained flat nuclei (thin arrows). H\&E $\times 400$.

\section{Effect of DOX and/or RSVL treatment on cell cycle phase} progression in Ehrlich cells

Treatment with RSVL induced accumulation of cells in $\mathrm{G}_{0} / \mathrm{G}_{1}$ phase after 24 hours, while DOX treatment showed 17 fold increase in the number of cells in $G_{0} / G_{1}$ phase with less number of cells in $S$ phase (Figure 3). Simultaneous treatment of RSVL with DOX resulted in increased number of cells in $G_{0} / G_{1}$ phase (about $85 \%$ ) with reduced number of cells in $\mathrm{S}$ phase compared to DOX or RSVL.

Three and twenty -four hours after DOX treatment the proliferation index (S phase $+\mathrm{G} 2 / \mathrm{M}$ phase) inhibited by about 6 and 78\%, respectively, whereas concomitant treatment with RSVL reduced the proliferation index significantly by about 29 and $85 \%$, respectively (Figure 4 ).

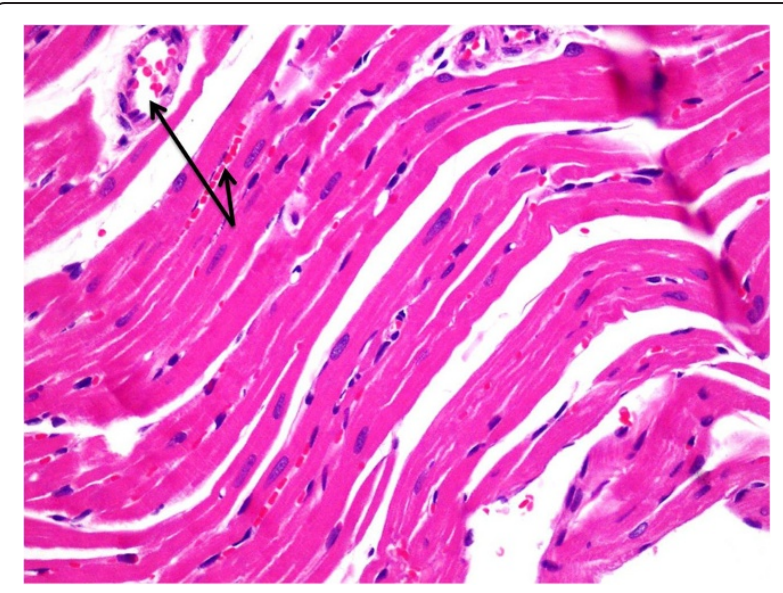

Figure 6 A photomicrograph of the myocardium of a rat given RSVL (10 mg/kg,i.p.) showing a general architecture almost similar to group I (control) except for slight congestion of the blood vessels (arrows). $\mathrm{H} \& \mathrm{E} \times 400$.

\section{Protective effect of RSVL against DOX-induced cardiotoxicity}

Light microscopic examination of heart section of albino rats after a single dose of RSVL (10 mg/kg,i.p.) showed a general architecture almost similar to control (Figures 5 and 6). However, DOX (20 mg/kg,i.p.) treated animals showed area of myocytolsis (Figure 7a) with congestion of blood vessels (Figure 7b), cytoplasmic vacuolization or fragmentation (Figure 7c). In addition there was hyalinization of the muscle fiber (Figure $7 \mathrm{~d}$ ) and chromatin margination of some nuclei while others were pyknotic (Figure 7e). Concomitant administration of RSVL ( $10 \mathrm{mg} / \mathrm{kg}$,i.p) with DOX showed normal muscle fibers with central oval nuclei and some pyknotic nuclei, while fragmentation of the muscle fiber were revealed (Figure 8).

\section{Discussion}

Doxorubicin is an excellent antitumor drug for treating several types of solid tumor, leukemia and lynphomas. However, acute or chronic toxicity is the dose limiting factor whereas, acute cardio toxicity represented mainly by transient symptoms, such as arrhythmias, while chronic toxicity can develop into irreversible cardiomyopathy, which affects approximately $30-40 \%$ of the patients who receive $500 \mathrm{mg} / \mathrm{mm}^{2}$ total dose [1]. In the current study we investigated the modulatory effect of a natural product RSVL on the cytotoxic activity of DOX against the growth of Ehrlich ascites carcinoma in mice. At the same time, its protective effect against DOX-induced cardiotoxicity was investigated. In this study, RSVL enhanced the cytotoxic activity of DOX against the growth of Ehrlich ascites carcinoma cells. Treatment of tumor bearing mice with RSVL + DOX showed 7 -fold increase in long-term survival in comparison to DOX treated mice alone (Table 1 and Figure 1). RSVL is known to has antitumor activity in vitro [9]. Our study showed high cellular level of DOX concentrations in Ehlrich cells when RSVL was concomitantly administered with DOX (Figure 2). There was an increase in DOX accumulation ratio for cells treated with DOX and RSVL. The increase in DOX cellular uptake inside Ehrlich cells may be explained based on inhibition of $\mathrm{P}$-glycoprotein that plays very important role in the absorption, distribution, and elimination of DOX and thus determine its efficacy and toxicity [13,14]. Supporting the previous work, cell cycle analysis showed that RSVL decreased the proliferation index ( $S$ phase $+G_{2} / M$ phase) of cells treated with DOX to 29 and 85\% compared with 6 and $78 \%$ in cells treated with DOX alone, 3 and 24 hours after DOX treatment, respectively. This agrees with the uptake study, where DOX uptake was at highest level 3 hours after DOX treatment. Al-Shabanh et al. [15] reported similar results where the peak of DOX uptake in tumor was observed three hours after DOX treatment. Recently, Osman et al. [9], showed high DOX concentration 


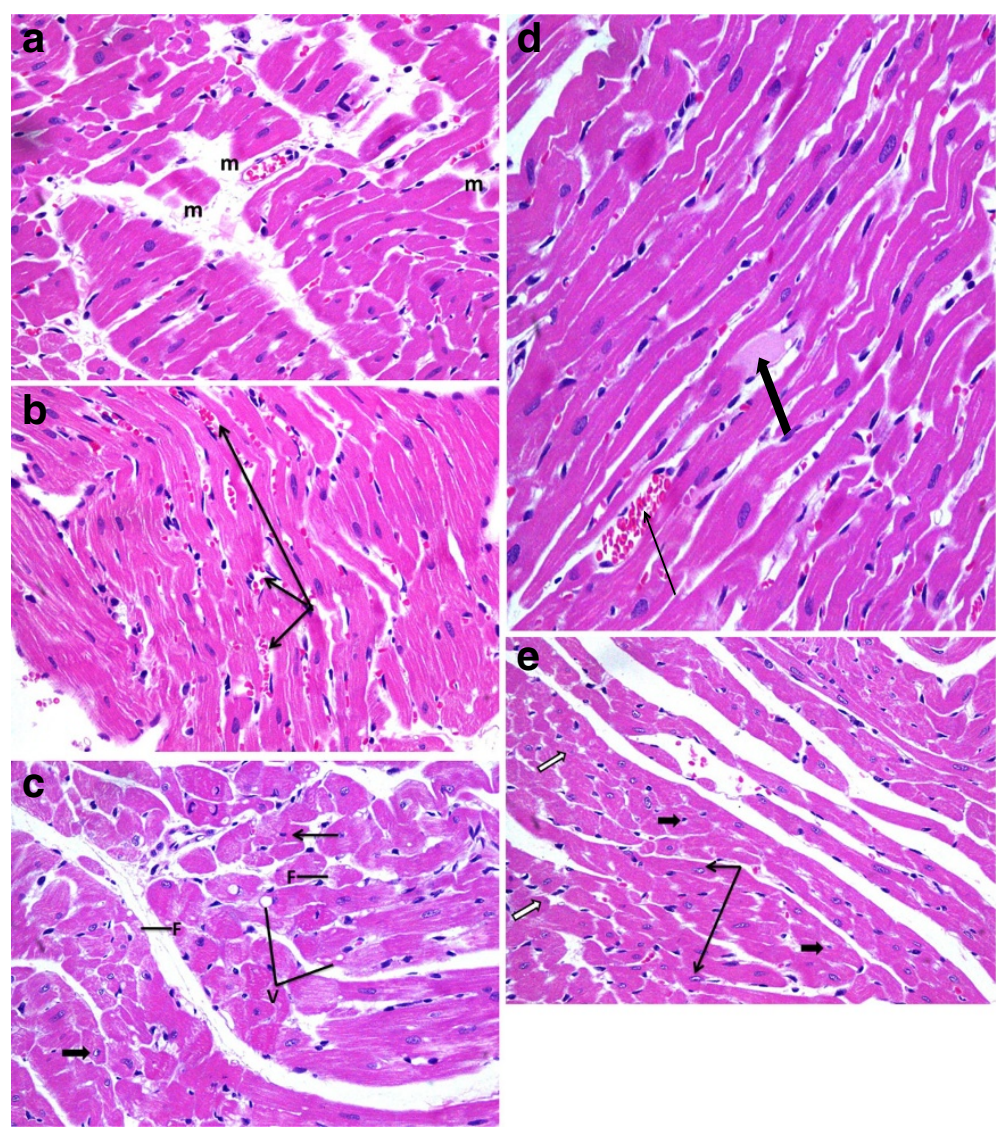

Figure 7 A photomicrograph of the myocardium of a rat given DOX ( $20 \mathrm{mg} / \mathrm{kg}, \mathrm{i} . \mathrm{p}$.) a :showing areas of myocytolysis $(\mathrm{m}) . \mathrm{H} \& \mathrm{E} \times 400$. b: showing congestion of blood vessels (arrows). H\&E $\times 400$. c: showing myocytes with cytoplasmic vacuolization $(V)$ or fragmentation (F). Some nuclei were pyknotic (thin arrow) while others revealed chromatin margination (thick arrow). $H \& E \times 400$. $\mathbf{d}$ : showing hyalinization of the muscle fiber (thick arrow). Notice the congested blood vessel (thin arrow). H\&E $\times 400$. e: showing chromatin margination of some nuclei (black arrows) while others were pyknotic (white arrows). Areas empty of muscle fibers around the pyknotic nuclei were evident (thick arrow). H\&E $\times 400$.

in MCF-7 cells when concomitantly administered with RSVL. It has been shown that P388 leukemia cells synchronized in $S$ and $G_{2} / M$ phases were more sensitive to DOX than cells in G1 phase [16], however, our study showed accumulation of Ehrlich cells in G1 phase by RSVL,DOX and their combination with significant decrease in number of cells in S phase which may be due inhibition of the enzyme used for DNA replication [17-19] or increase expression of positive $G_{1} / S$ regulators, such as cyclin D1 and cyclin $\mathrm{E}$ which are responsible for $\mathrm{S}$ phase entry $[20,21]$. Although our finding is somehow contradictory to other results reported a significant accumulation of some cancer cells in S-phase after RSVL treatment [22] This could be due to different cell lines used and the deregulation of expression and/or activities of different isoforms of cyclins and CDKs [23].

RSVL which is known to display antitumor activity [24], has been shown to have potent cardioprotective effect. This was observed in our study, where DOX

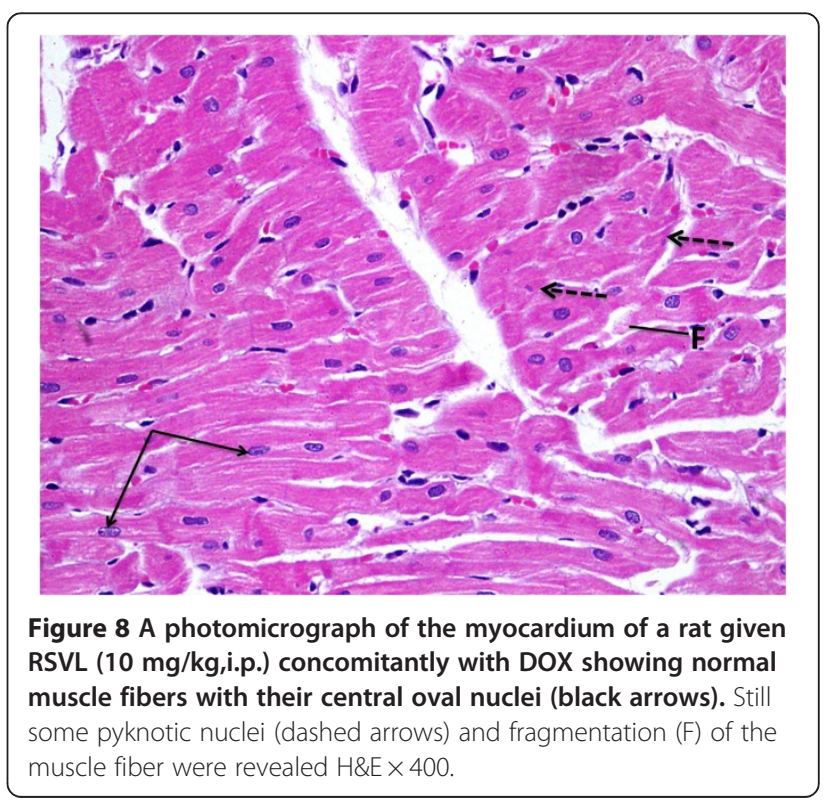


treatment DOX showed cardiac myocytes with cytoplasmic vacuolization or fragmentation. Some nuclei were pyknotic while others revealed chromatin margination (Figure 7a, $7 \mathrm{~b}, 7 \mathrm{c}$ ). In the presence of RSVL cardiac myocytes showed normal muscle fibers with their central oval nuclei in addition to some pyknotic nuclei and fragmentation of the muscle fiber (Figure 8). In animal models of cardiovascular disease, RSVL has been shown to protect the heart from ischemi reperfusion injury, reduce blood pressure and cardiac hypertrophy on hypertensive animals and has been shown to slow progressionof athrosclerosis [25]. The exact mechanism of cardioprotective is not understood, but it could be due to inhibition of DOX-induction of the rapid increase in ROS accumulation in cardiac cell mitochondria [26] by increasing superoxide dismutase activity [27], suggesting that the antioxidant properties of resveratrol may play a role in its cardioprotective effects. However, antioxidant therapies have failed to produce satisfactory results in clinical trials [28], casting doubt on the notion that the inhibition of oxidative stress is the only mechanism responsible for the cardioprotective effects of resveratrol which may need further investigations. In conclusion, this study suggests that RSVL treatment increased the cytotoxic activity of DOX against the growth of Mammary tumor in vivo and could be as a promising cardioprotective agent against DOX-induced cardiotoxicity.

\section{Competing interests}

The authors declare that they have no competing interest.

\section{Authors' contributions}

$\mathrm{AMO}, \mathrm{SEA}, \mathrm{OMA}, \mathrm{HMA}, \mathrm{ZAD}, \mathrm{MNA}$ and $\mathrm{OHO}$ sharing in experimental work and writing the manuscript. MFA did the flow cytometric analysis and interpreted the results and WSR investigated the pathological changes in the hearts together with NMA. All authors read approved the final manuscript.

\section{Author details}

'Pharmacology Department, Faculty of Medicine, King Abdulaziz University, Jeddah, Saudi Arabia. ${ }^{2}$ National Cancer Institute, Cairo University, Cairo, Egypt. ${ }^{3}$ Princess Al-Jawhara Center of Excellence in Research of Hereditary Disorders, Jeddah, Saudi Arabia. ${ }^{4}$ Department of Biochemistry, Faculty of Science, King Abdulaziz University, Jeddah, Saudi Arabia. ${ }^{5}$ Molecular biology Department, Genetic engineering and Biotechniology Department, Minoufia University, Minoufia, Egypt. ${ }^{6}$ Department of Anatomy, Faculty of Medicine, King Abdulaziz University, Jeddah, Saudi Arabia. ${ }^{7}$ Department of Medicine, Cardiology unit, Faculty of Medicine, King Abdulaziz University, Jeddah, Saudi Arabia.

\section{Received: 25 February 2013 Accepted: 14 May 2013}

Published: 28 May 2013

\section{References}

1. Lefrak EA, Pita J, Rosenheim S, Gofottiebm JA: A clinicopathological analysis of adriamycin cardiotoxicity. Cancer 1973, 32:302-314

2. Singal PK, lliskovic N: Doxorubicin-induced cardiomyopathy. N Engl J Med 1997, 339:900-905.

3. Osman AM, Al-Shabanh OA, Al-Harbi MM, Al-Gharabli N, Al-Bekiri A: Effectf of desferrioxamine on the doxorubicin-induced cardiotoxicity and haematotoxicity in mice. Med Sci Res 1993, 21:193-194.

4. Osman AM, Marowa MN, Amany AE, Omimah AN, Khyyal MT: Effect of methimazole treatment on doxorubicin-induced cardiotoxicity. Food Chem Toxicol 2009, 47:2425-2430.
5. Al-Kreathy HM, Zoheir AD, Nessar A, Mark S, Osman AM: Mechanisms of cardioprotective effect of aged garlic extract Against doxorubicininduced cardiotoxicity. Integr Canc Ther 2011, 15:364-371.

6. Goswami SK, Das DK: Resveratrol and chemoprevention. Canc Lett 2009, 284:1-6.

7. Cal C, Garban H, Jazirehi A, Yeh C, Mizutani Y, Bonavida B: Resveratrol and cancer: chemoprevention, apoptosis and chemoimmunosensitizing activities. Curr Med Chem Anticanc Agent 2003, 3(2):77-93.

8. Alkreathy HM, Damanhour ZA, Nessae A, Mark Ali SS, Osman AM: Aged garlic extract protects against doxorubicin-induced cardiotoxicity in rats. Food Chem Toxicol 2010, 48:951-956.

9. Osman AM, Bayoumi HM, Al-Harthy SA, Damanhouri ZA, AlShal M: Modulation of doxorubicin cytotoxicity by resveratrol in a human breast cancer cell line. Canc Cell Int 2012, 12:47-53.

10. Donenko FV, Efferth T, Mattern J, Moroz LV, Volm M: Resistance to doxorubicin in tumor cells in vitro and in vivo after pretreatment with verapamil. Chemotherapy 1991, 37:57-61.

11. Kitagawa S, Nabekura T, Kamiyama S: Inhubition of P-glycoprotein function by tea catechins in KB-C2 cells. J Pharm Pharmacol 2005, 56(8):1001-1005.

12. Smets LA, Bout B, Broiwer M, Tulp A: Cytotoxic effect of dexamethasone restricted to noncycling early $G_{1}$ phase cells of $L 1210$ leukemia. J Cell Physiol 1983, 116(3):397-403.

13. Kim HS, Kim TH: Resveratrol enhances the sensitivity of doxorubicinmediated cell proliferation,invasion, and migration in human breast cancer cell lines. FASEB J 2010, 964:10.

14. Al-Abd AM, Mahmoud AM, El-Sherbiny GA, El-Moselhy MA, Nofal SM, El-Latif HA, El-Eraky WI, El-Shemy HA: Resveratrol enhances the cytotoxic profile of docetaxel and doxorubicin in solid tumor cell lines in vitro. Cell Prolif 2011, 44(6):591-601.

15. Al-Shabanh OA, Osman AM, Al-Harbi MM, Al-Bekairi AM, Al-Gharably NM, Aziz SA: Diltiazem potentiation of doxorubicin cytotoxicity and cellular up take in Ehrlich ascites carcinoma cells. Chemotherapy 1995, 41(5):368-377

16. Najjar $\mathrm{H}$, Easson $\mathrm{A}$ : Age at diagnosis of breast cancert in arab nations. Int J Surg 2010, 8(6):448-452.

17. Ragione FD, Cucciolla V, Borriello A, Pietra VD, Racioppi L, Soldati G, Manna C, Galletti P, Zappia V: Resveratrol arrests the cell division cycle at S/G2 phase transition. Biochem Biophys Res Commun 1998, 250(1):53-58

18. Gusman J, Malooe $H$, Atassi G: A reappraisal of the potential chemopreventive and chemotherapeutic properties of resveratrol. Carcinogenesis 2001, 22(8):1111-1117.

19. Joe AK, Liu H, Suzui M, Vural ME, Xiao D, Weinstein IB: Resveratrol induces growth inhibition, S- phase arrest, apoptosis, and changes in biomarker expression in several human cancer cell lines. Clin Canc Res 2002, 8:893-903.

20. Huang C, Ma WY, Goranson A, Dong Z: Resveratrol suppresses cell transformation and induces apoptosis through a P53-dependent pathway. Carcinogenesiss Lond 1999, 20(2):237-242.

21. Pozo-Guisado E, Alvarez-Barrientos A, Mulero-Navarro S, Santiago-Josefat B, Fernandez-Salguero PM: The antiproliferative activity of resveratrol results in apoptosis in MCF-7 but not in MDA-MB-231 human breast cancer cells: cell-specific alteration of the cell cycle. Biochem Pharmacol 2002, 64(9):1375-1386.

22. Chen Y, Tseng SH, Lai HS, Chen WJ: Resveratrol-induced cellular apoptosis and cell cycle arrest in neuroblastoma cells and antitumor effects on neuroblastoma in mice. Surgery 2004, 136(1):57-66.

23. Hao J, Lijie Z, Jarret K, Kelly K, Gautam SC, Laurent G, Rodriguez Al, David K, Tangella Jackson H, Corcoran GB, Seidman MD, Levine RA: induced apoptotic death in human U251 glioma cells. Mol Canc Ther Resveratrol 2004, 4:554-557.

24. Aggarwal BB, Bhardwaj A, Aggarwal RS, Seeram NP, Shishodia S, Takada $Y$ : Role of resveratrol in prevention and therapy of cancer: preclinical and clinical studies. Anticanc Res 2004, 24(5A):2783-2840.

25. Li H, Xia N, Forstermann U: Cardiovascular effects and molecular targets of resveratrol. Nitric Oxide 2012, 26(2):102-110.

26. Danz ED, Skramsted J, Henry N, Bennett JA, Keller RS: Resveratrol prevents doxorubicin cardiotoxicity through mitochondrial stabilization and the Sirt1 pathway.Free radic. Biol Med 2009, 46(12):1589-1597. 
27. Tatlidede E, Sehirli O, Velioğlu-Oğünc A, Cetinel S, Yeğen BC, Yarat A, Süleymanoğlu S, Sener G: Resveratrol treatment protects against doxorubicin-induced cardiotoxicity by alleviating oxidative damage. Free Radic Res 2009, 43:195-205.

28. Gianni L, Herman EH, Lipshultz SE, Minotti G, Sarvazyan N, Sawyer DB: Anthracycline cardiotoxicity: from bench to bedside. J Clin Oncol 2008, 26:3777-3784

doi:10.1186/1475-2867-13-52

Cite this article as: Osman et al: Chemosensetizing and cardioprotective

effects of resveratrol in doxorubicin- treated animals. Cancer Cell

International 2013 13:52.

\section{Submit your next manuscript to BioMed Central and take full advantage of:}

- Convenient online submission

- Thorough peer review

- No space constraints or color figure charges

- Immediate publication on acceptance

- Inclusion in PubMed, CAS, Scopus and Google Scholar

- Research which is freely available for redistribution 